\title{
Morus alba L. suppresses the development of atopic dermatitis induced by the house dust mite in NC/Nga mice
}

\author{
Hye-Sun Lim, Hyekyung Ha, Hoyoung Lee, Jun Kyung Lee, Mee-Young Lee and Hyeun-Kyoo Shin*
}

\begin{abstract}
Background: Morus alba, a medicinal plant in Asia, has been used traditionally to treat diabetes mellitus and hypoglycemia. However, the effects of M. alba extract (MAE) on atopic dermatitis have not been verified scientifically. We investigated the effects of MAE on atopic dermatitis through in vitro and in vivo experiments.

Methods: We evaluated the effects of MAE on the production of nitric oxide $(N O)$ and prostaglandin $E_{2}\left(P G E_{2}\right)$ in RAW 264.7, as well as thymus and activation-regulated chemokine (TARC/CCL17) in HaCaT cells. In an in vivo experiment, atopic dermatitis was induced by topical application of house dust mites for four weeks, and the protective effects of MAE were investigated by measuring the severity of the skin reaction on the back and ears, the plasma levels of immunoglobulin $\mathrm{E}(\mathrm{IgE})$ and histamine, and histopathological changes in the skin on the back and ears.

Results: MAE suppressed the production of $\mathrm{NO}$ and PGE 2 in RAW 264.7 cells, as well as TARC in HaCaT cells, in a dose-dependent manner. MAE treatment of NC/Nga mice reduced the severity of dermatitis and the plasma levels of IgE and histamine. MAE also reduced the histological manifestations of atopic dermatitis-like skin lesions such as erosion, hyperplasia of the epidermis and dermis, and inflammatory cell infiltration in the skin on the back and ears.

Conclusion: Our results suggest that MAE has potent inhibitory effects on atopic dermatitis-like lesion and may be a beneficial natural resource for the treatment of atopic dermatitis.
\end{abstract}

Keywords: Atopic dermatitis, Keratinocyte, Macrophage, Morus alba, NC/Nga mouse

\section{Background}

Atopic dermatitis is a multifactorial disease that depends on a genetic predisposition to allergy, which is characterized by complex immune mechanisms in the development of allergic skin inflammation [1]. Complex interrelationships between genetic, environmental, skin barrier, pharmacological, psychological and immunological factors contribute to the pathogenesis of atopic dermatitis, but its immunological basis is of considerable importance, and it has been studied extensively [2]. Immunological analyses of atopic dermatitis have shown that the activation of mast cells and differentiated T-helper 2 (Th2) cells by various

\footnotetext{
* Correspondence: hkshin@kiom.re.kr

Herbal Medicine Formulation Research Group, Korea Institute of Oriental Medicine, 1672 Yuseong-daero, Yuseong-gu, Daejeon 305-811, Republic of Korea
}

\section{() Biomed Central}

mediators have major roles in the development of dermatitis [3,4]. Previous studies have shown that atopic dermatitis is associated with increased serum immunoglobulin (Ig) E levels, the Th2 chemokine level in the lesional skin, the serum eosinophil count, and the expression of proinflammatory enzymes such as nitric oxide $(\mathrm{NO})$ and prostaglandin $\mathrm{E}_{2}\left(\mathrm{PGE}_{2}\right)[5,6]$.

Morus alba L. (Moraceae) is a traditional medicinal herb used for the prevention and treatment of several diseases, such as jaundice, hematemesis, and pollakisuria $[7,8]$. Phytochemical studies of $M$. alba have identified alkaloids, flavonoids, glycosides, terpenoids, steroids, volatile oils and tannins [9-11]. The biological activities of $M$. alba include antidiabetic, hypolipidemic, antihypertensive, antimicrobial, antioxidant, antiatherosclerotic, anticancer, neuroprotective, and antiulcer effects [12-16]. 
However, there was no study on the effects of $M$. alba on atopic dermatitis. Therefore, we investigated the effect of M. alba extract (MAE) on $\mathrm{NO}$ and $\mathrm{PGE}_{2}$ production in RAW 264.7 macrophages, and thymus and activationregulated chemokine (TARC) production in $\mathrm{HaCaT}$ keratinocytes. We examined the effects of MAE on $\mathrm{NC} / \mathrm{Nga}$ mice as a model of house dust mite-induced atopic dermatitis. We measured the skin severity score, histological changes in the skin, including mast cell infiltration, and the plasma IgE and histamine levels. The effect of MAE might be associated with the suppression of the inflammatory response in atopic dermatitis.

\section{Methods}

\section{Reagents and materials}

Dried M. alba (200 g) was extracted three times with $70 \%$ ethanol ( $2 \mathrm{~L}$ ) by sonication for $60 \mathrm{~min}$. The extract was filtered, evaporated to dryness, and freeze-dried $(11.35 \mathrm{~g})$. The yield was $5.68 \%$. The $M$. alba used in this experiment was purchased from HMAX (Jecheon, Korea) in October 2008. The origin of the sample was confirmed taxonomically by Professor Je-Hyun Lee, Dongguk University, Gyeongju, Republic of Korea. A specimen (2008-ST12) has been deposited in the Basic Herbal Medicine Research Group, Korea Institute of Oriental Medicine.

Biostir- $\mathrm{AD}^{\circ}$, an ointment that contains house dust mite (Dermatophagoides farina) extract, was purchased from Biostir Inc. (Kobe, Japan), while 0.1\% Tacrolimus (Protopic ${ }^{\circ}$; Astellas, Grand Island, NY, USA) was used as a the positive control.

\section{Cell culture}

The murine macrophage RAW 264.7 cells and human keratinocyte $\mathrm{HaCaT}$ cells were obtained from the American Type Culture Collection (Rockville, MD, USA). They were cultured in Dulbecco's modified Eagle's medium (Gibco Inc., Grand Island, NY, USA) supplemented with 5.5\% (for Raw 264.7) or 10\% (for HaCaT) heatinactivated fetal bovine serum (Gibco Inc.), penicillin $(100 \mathrm{U} / \mathrm{mL})$, and streptomycin $(100 \mu \mathrm{g} / \mathrm{mL})$ in a $5 \% \mathrm{CO}_{2}$ incubator at $37^{\circ} \mathrm{C}$.

\section{Cell viability}

Cell viability was assessed with the CCK- 8 assay (Cell Counting Kit-8, Dojindo Laboratories, Kumamoto, Japan) according to the manufacturer's instructions. RAW 264.7 cells $\left(3 \times 10^{3}\right.$ cells/well $)$ and $\mathrm{HaCaT}$ cells $\left(1 \times 10^{3}\right.$ cells/well $)$ were incubated in 96-well plates with various concentrations of the MAE for $24 \mathrm{~h}$. CCK- 8 reagent was added to each well and incubated for $4 \mathrm{~h}$. The absorbance was measured at $450 \mathrm{~nm}$ with a Benchmark plus microplate reader (Bio-Rad Laboratories, Hercules, CA, USA). The percentage of cell viability was calculated with the following formula: cell viability $(\%)=$ (mean absorbance in test wells/ mean absorbance in control wells) $\times 100$.

\section{Measurement of nitrite and $\mathrm{PGE}_{2}$ production}

RAW 264.7 cells were plated at a density of $2.5 \times 10^{5}$ cells/well on 48-well plates and incubated overnight. The cells were treated with lipopolysaccharide (LPS, $1 \mu \mathrm{g} / \mathrm{mL}$ ) in the absence or presence of various concentrations of MAE. After incubation for $24 \mathrm{~h}$, the supernatants were used to determine the levels of nitrite (Griess Reagent System, Promega Co., Madison, WI, USA) and $\mathrm{PGE}_{2}$ $\left(\mathrm{PGE}_{2}\right.$ enzyme linked immunosorbent assay (ELISA) kit, Cayman Chemical Co., Ann Arbor, MI, USA).

\section{Measurement of TARC production}

HaCaT cells $\left(1 \times 10^{6}\right.$ cell/well $)$ were cultured on six-well plates. After reaching a confluent state, the cells were washed and treated with MAE in $1 \mathrm{~mL}$ of serum-free medium containing tumor necrosis factor (TNF)- $\alpha$ and interferon (IFN)- $\gamma$ (each $10 \mathrm{ng} / \mathrm{mL}$; R\&D Systems Inc., Minneapolis, MN, USA) for $24 \mathrm{~h}$. The supernatants were harvested, and TARC production was quantified using an ELISA kit (R\&D Systems Inc., Minneapolis, MN, USA).

\section{Experimental animals}

Male NC/Nga mice (eight weeks old) were purchased from Central Laboratory Animal Inc. (Seoul, Korea). The animals were housed in an air-conditioned room and maintained at $24 \pm 2^{\circ} \mathrm{C}$ and $55 \pm 15 \%$ humidity. All experimental procedures were carried out in accordance with the NIH Guidelines for the Care and Use of Laboratory Animals and were approved by Korea Institute of Oriental Medicine Institutional Animal Care and Use Committee (Approval number: \#10-052).

\section{Induction of atopic dermatitis in $\mathrm{NC} / \mathrm{Nga}$ mice}

Atopic dermatitis-like skin lesions were induced in 10-week-old male NC/Nga mice using Biostir-AD, as described by the manufacturer with some modifications [17]. Briefly, the upper back was shaved, and $200 \mu \mathrm{L}$ of $4 \%$ $(w / v)$ sodium dodecyl sulfate (SDS) was applied to the shaved dorsal skin and both surfaces of each ear for barrier disruption. After 2 h, 50 mg of Biostir-AD was applied topically and twice per week for four weeks. The mice were allocated to four random groups ( $n=7 /$ group): normal control group (vehicle-treated mice; 70\% ethanol/PBS (ratio 1:9), $200 \mu \mathrm{L} /$ mouse), Biostir group (Biostir-AD plus vehicle-treated mice), Tacrolimus group (Biostir-AD plus Tacrolimus ointment-treated mice; $50 \mu \mathrm{g} /$ mouse), and MAE group (Biostir-AD plus MAE-treated mice; $10 \mathrm{mg} /$ mouse). The effective dose of MAE was determined according to preliminary study. We have used $10 \mathrm{mg} / \mathrm{kg}$ and $20 \mathrm{mg} / \mathrm{kg}$ of MAE as experimental doses in preliminary study. The procedure of preliminary study was same to present study. 
The skin severity significantly decreased in both 10 and $20 \mathrm{mg} / \mathrm{kg}$ of MAE compared with the animal with atopic dermatitis. However, the skin severity of $10 \mathrm{mg} / \mathrm{kg}$ more decreased than that of $20 \mathrm{mg} / \mathrm{kg}$. MAE was dissolved $70 \%$ ethanol/PBS (ratio = 1:9) and applied every day for four weeks. The mice were sacrificed under anesthesia with pentobarbital (200 $\mu \mathrm{g} /$ mouse, i.p.) on the day of the experiment. During the autopsy, blood was collected from the posterior vena cava, and the back skin and each ear were excised for the histopathological analyses.

\section{Evaluation of skin severity}

The relative severity of dermatitis was assessed macroscopically according to the Eczema Area and Severity Index (EASI) scoring system: 0, no symptoms; 1, mild symptoms; 2 , moderate symptoms; and 3 , severe symptoms. The dermatitis score was defined as the sum of the scores for erythema/hemorrhage, edema, excoriation/erosion, and scaling/dryness [18]. The range of dermatitis score is 0 to 12 . The mice were also photographed once each week. The dermatitis scoring is conducted throughout blind test. Two veterinarian and three animal study experts participated in blind test.

\section{Histopathology}

After sacrifice, the back skin and one ear of each mouse were fixed in $10 \%(\mathrm{v} / \mathrm{v})$ neutral buffered formalin for $24 \mathrm{~h}$ at $4^{\circ} \mathrm{C}$. Tissue samples were embedded in paraffin and thin-sectioned ( $4 \mu \mathrm{m}$ thickness). The sections were stained with hematoxylin and eosin (H\&E) solution (Sigma-Aldrich, St. Louis, MO, USA) and mounted under cover slips using Dako-mounting medium (Dako Cytomation, Glostrup, Denmark). The stained sections were photographed using a photometric Quantix digital camera, and montages were assembled using Adobe Photoshop. To measure the degree of mast cell infiltration, the skin sections were stained with toluidine blue, and the numbers of mast cells were counted in four sites. The histological alternation of tissue was examined by two histopathologists.

\section{Measurement of plasma lgE and histamine levels}

Blood samples were drawn from the mice, separated by centrifugation at $10000 \times \mathrm{g}$ for $10 \mathrm{~min}$ at $4^{\circ} \mathrm{C}$, and stored at $-80^{\circ} \mathrm{C}$. The levels of histamine (Oxford Biomedical Research, Oxford, MI, USA) and IgE (Bethyl Laboratories Inc., Montgomery, TX, USA) were measured in the plasma using ELISA kits, according to the manufacturer's instructions.

\section{Statistical analyses}

All of in vitro experiments were performed at least three times. The dermatitis score was analyzed using Mann-Whitney's U test. The concentration of IgE, histamine, $\mathrm{PGE}_{2}$, nitrite and TARC were analyzed by one-way analysis of variance (ANOVA) followed by Dunnett's test. The difference was considered significant at $P<0.05$.

\section{Results}

\section{MAE inhibits nitrite and $\mathrm{PGE}_{2}$ production in LPS-stimulated} RAW264.7 cells

The cytotoxicity of MAE was determined in RAW 264.7 and $\mathrm{HaCaT}$, subsequent experiments were performed in cells at non-toxic concentrations (Figure 1). To determine the effects of $\mathrm{MAE}$ on nitrite and $\mathrm{PGE}_{2}$ production, RAW264.7 cells were treated with various concentrations of $\operatorname{MAE}(1,10$, or $100 \mu \mathrm{g} / \mathrm{mL})$ followed by stimulation with LPS $(1 \mu \mathrm{g} / \mathrm{mL})$ for $24 \mathrm{~h}$. LPS strongly stimulated nitrite production $(51.01 \pm 2.178 \mathrm{nM})$ in RAW 264.7 cells. By contrast, MAE significantly reduced nitrite production $(24.20 \pm 1.818 \mathrm{nM}, P<0.01)$ at a dose of $100 \mu \mathrm{g} / \mathrm{mL}$ compared with that in the LPS-stimulated RAW 264.7 cells (Figure 2A). LPS-stimulated RAW 264.7 cells had higher $\mathrm{PGE}_{2}$ production $(9.90 \pm 0.957 \mathrm{ng} / \mathrm{mL}, P<0.05)$ compared with the untreated control $(5.43 \pm 0.502 \mathrm{ng} / \mathrm{mL})$, whereas MAE reduced the $\mathrm{PGE}_{2}$ level significantly $(6.28 \pm 0.102 \mathrm{nM}$, $P<0.05)$ at $100 \mu \mathrm{g} / \mathrm{mL}$ compared with LPS stimulation (Figure 2B).

\section{MAE inhibits TARC production in TNF- $\alpha$ and IFN- $-\gamma$ stimulated $\mathrm{HaCaT}$ cells}

We tested the effects of MAE on TARC production in TNF- $\alpha$ and IFN- $\gamma$ (TI)-stimulated HaCaT cells. The cells were treated with various concentrations of MAE extract $(20,50$, or $100 \mu \mathrm{g} / \mathrm{mL})$ followed by stimulation with TI (10 ng/mL) for $24 \mathrm{~h}$. MAE suppressed TI-stimulated TARC production in a dose-dependent manner (Figure 3). The TI-treated cells exhibited a significant increase in TARC production $(24.43 \pm 0.879 \mathrm{pg} / \mathrm{mL}, P<0.01)$ compared with the untreated control cells $(2.44 \pm 0.437 \mathrm{pg} / \mathrm{mL})$. The increased of TARC production was reduced to $12.79 \pm 1.955 \mathrm{pg} / \mathrm{mL}, 3.69 \pm 0.835 \mathrm{pg} / \mathrm{mL}$, and $1.83 \pm$ $0.895 \mathrm{pg} / \mathrm{mL}$ by MAE treatment $(P<0.01)$ at 20,50 , or $100 \mu \mathrm{g} / \mathrm{mL}$, respectively.

MAE suppresses the severity of dermatitis and skin lesions in Biostir-AD-induced atopic dermatitis using NC/Nga mice The severity of dermatitis was evaluated once each week. The major clinical signs and symptoms developed shortly after the mite antigen was applied to the backs of the mice. The atopic dermatitis-like skin lesions worsened progressively for four weeks after the initial treatment. Repeated application of Biostir-AD ointment induced skin dryness, followed by mild erythema, hemorrhage, and edema (Figure 4A). Finally, the skin became thick, with severe erythema, hemorrhage, edema, scarring, erosion and excoriation. However, the application of MAE suppressed these skin symptoms. The dermatitis score of each group was determined by summing the eczema area severity 

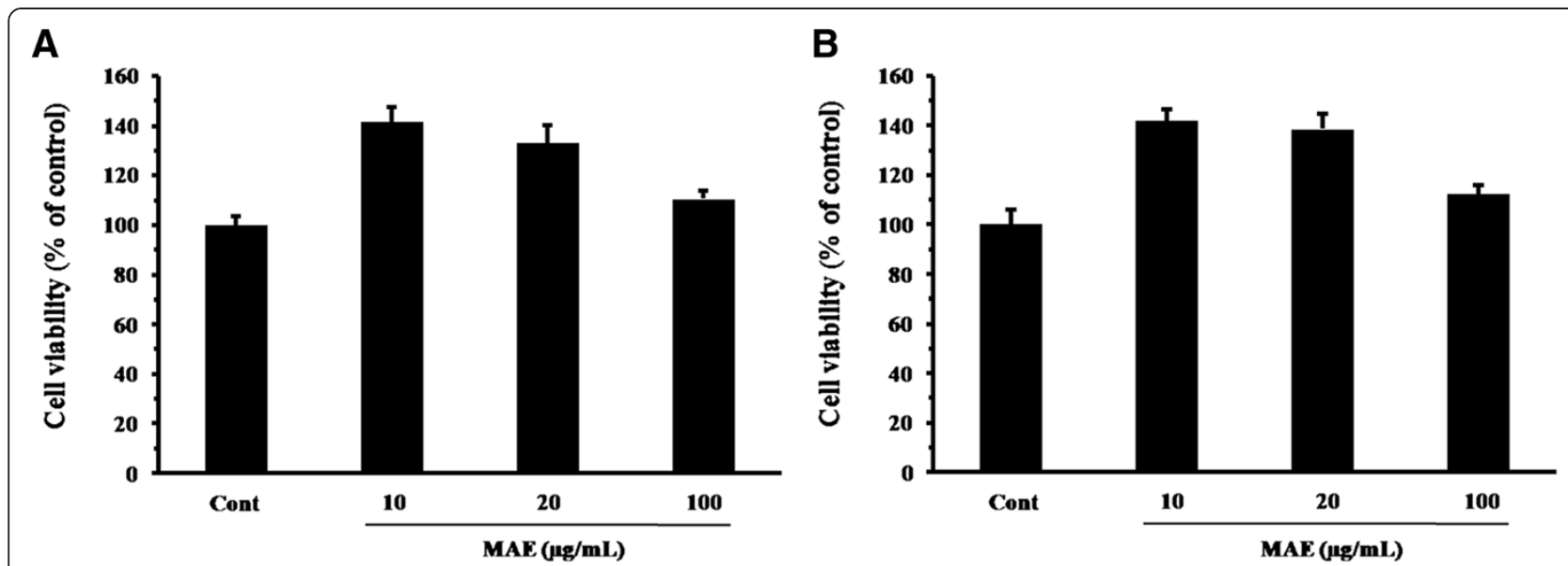

Figure 1 Cytotoxicity of MAE in RAW 264.7 (A) and HaCaT cells (B). Cells were seeded into 96-well plates and treated with MAE $(10,20$, or $100 \mu \mathrm{g} / \mathrm{mL})$ for $24 \mathrm{~h}$. Cell viability was assessed using a CCK-8 assay.

index (EASI) values of each mouse (Figure 4B). In the Tacrolimus group, the symptoms increased for three weeks but declined thereafter. In the MAE group, the dermatitis score was lower at three weeks compared with the Biostir group. These results indicate that MAE suppressed the spontaneously induced dermatitis in NC/Nga mice.

MAE attenuates the atopic dermatitis-like lesions induced by Biostir-AD

The histopathological features were assessed using specimens from the back skin and ears of NC/Nga mice. As shown in Figure 5, epidermal hyperplasia, parakeratosis, hyperkeratosis, dermal edema, and a large numbers or infiltrated of inflammatory cells were observed in the control group. However, sections of the skin from the back and ears of the MAE-treated group exhibited remarkable reductions in epidermal hyperplasia and cellular infiltration into the dermis. These results suggest that MAE suppressed the Biostir-AD-induced inflammation. The normal group showed no signs of inflammation.

\section{MAE inhibits the IgE and histamine levels in} Biostir-AD-induced atopic dermatitis in NC/Nga mice The plasma levels of total IgE and histamine were determined in the NC/Nga mouse model. We found that Biostir-AD $(266.53 \pm 14.92 \mathrm{ng} / \mathrm{mL}, P<0.01)$ increased the level of IgE compared with the control group $(56.67 \pm 14.91 \mathrm{ng} / \mathrm{mL})$, whereas the IgE levels in mice administered with MAE $(186.01 \pm 8.07 \mathrm{ng} / \mathrm{mL}, P<0.05)$ were lower than those in the Biostir group (Figure 6A). The MAE-treated group $(932.47 \pm 84.89 \mathrm{nM})$ had lower
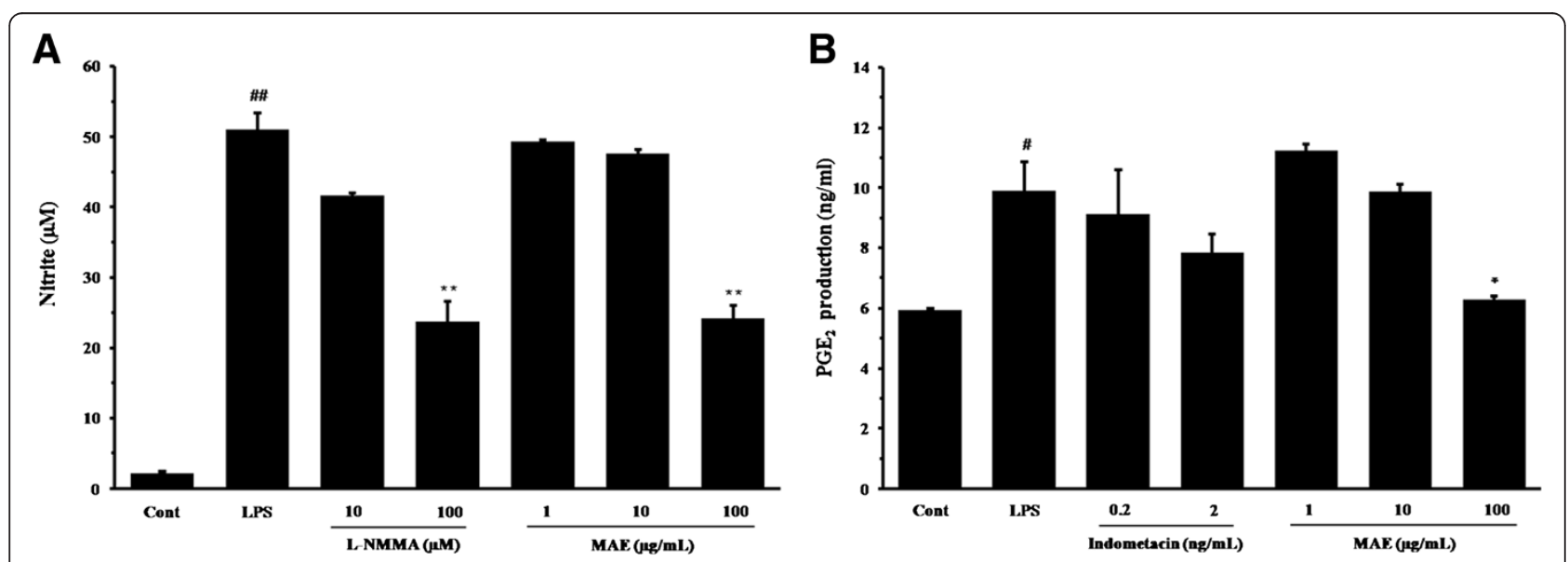

Figure 2 Effects of MAE on LPS-stimulated nitrite and $\mathrm{PGE}_{2}$ production in RAW 264.7 cells. The productions of nitrite (A) and PGE 2 (B) was measured using the culture supernatant from cells co-treated with MAE $(1,10$, or $100 \mu \mathrm{g} / \mathrm{mL})$ and LPS $(1 \mu \mathrm{g} / \mathrm{mL})$ for $24 \mathrm{~h}$. L-NMMA (10 and $100 \mu \mathrm{MM})$ and indomethacin $\left(0.2\right.$ and $2 \mathrm{ng} / \mathrm{mL}$ ) were used as positive control drugs. The bar groups represent means from three independent experiments. ${ }^{\# \# ~} P<0.01$ vs. vehicle control group; ${ }^{*}{ }^{* *} P<0.05$ and $P<0.01$ vs LPS-treated cells, respectively. 


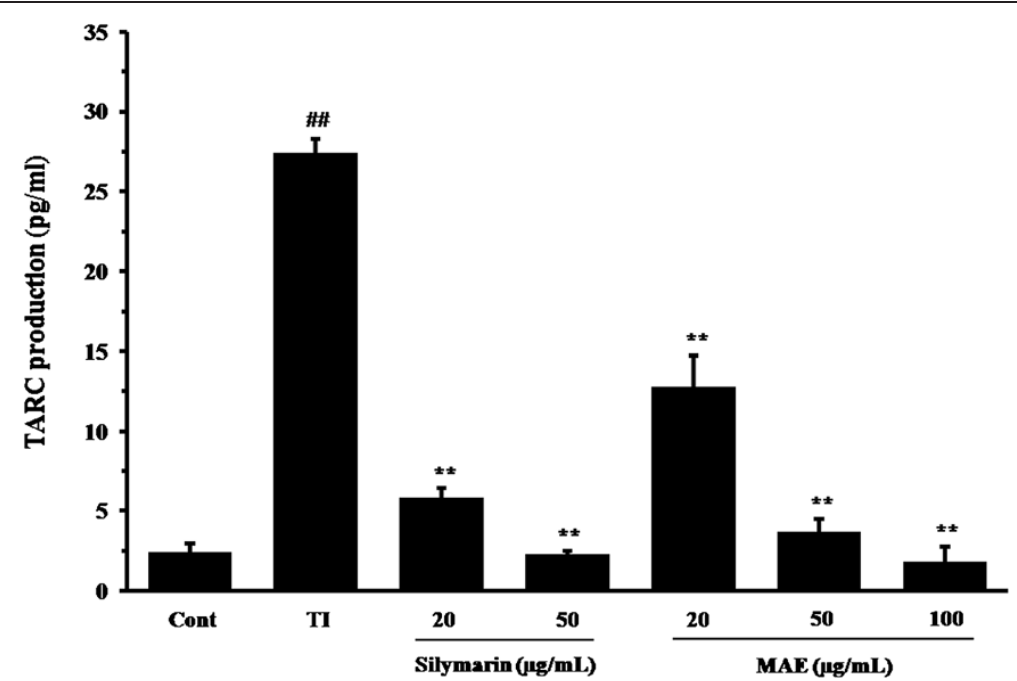

Figure 3 Effects of MAE on TNF- $\alpha$ - and IFN- $\boldsymbol{\gamma}$-stimulated TARC production in HaCaT cells. The production of TARC was measured using the culture supernatant from the cells co-treated with MAE $(20,50$, or $100 \mu \mathrm{g} / \mathrm{mL})$, and TNF-a and IFN- $\mathrm{(each} 10 \mathrm{ng} / \mathrm{mL}$, TI) for 24 h. Silymarin ( 20 or $50 \mu \mathrm{g} / \mathrm{mL}$ ) was used as a positive control drug. The bar groups represent the means from three independent experiments. ${ }^{\# \#} P<0.01 \mathrm{vs}$ vehicle control group; ${ }^{* *} P<0.01$ vs. Tl-treated cells.

histamine levels compared with the Biostir group $(1266.69 \pm 147.25 \mathrm{nM}$ ) (Figure 6B), although the difference was not significant. These results demonstrate that MAE prevented the development of atopic dermatitis in $\mathrm{NC} / \mathrm{Nga}$ mice.

\section{Discussion}

Atopic dermatitis is a chronic inflammatory skin disease, which is characterized by pruritic and eczematous skin lesions. Recently, atopic dermatitis has been increasing in industrialized countries, and it is a multifactorial disease

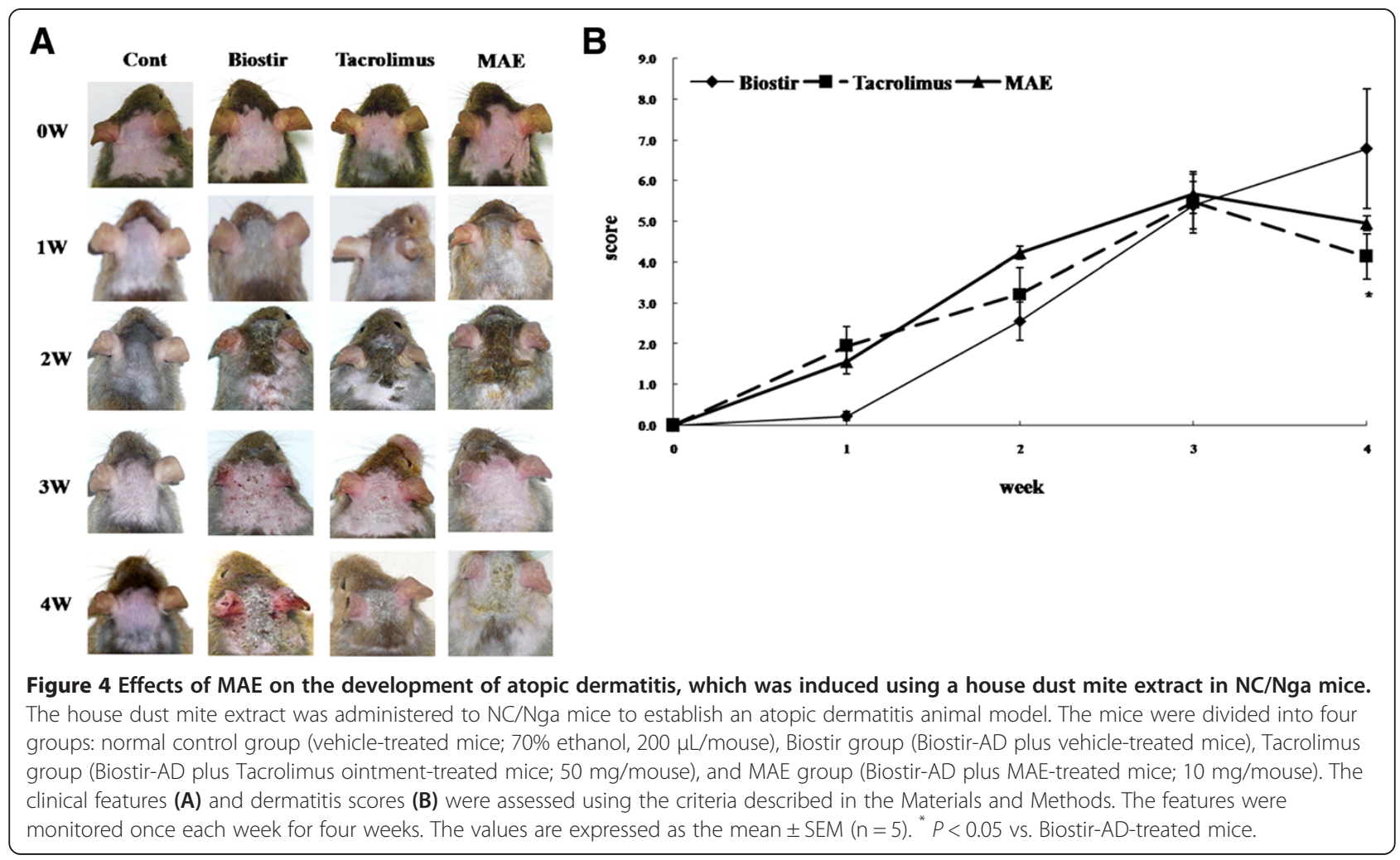




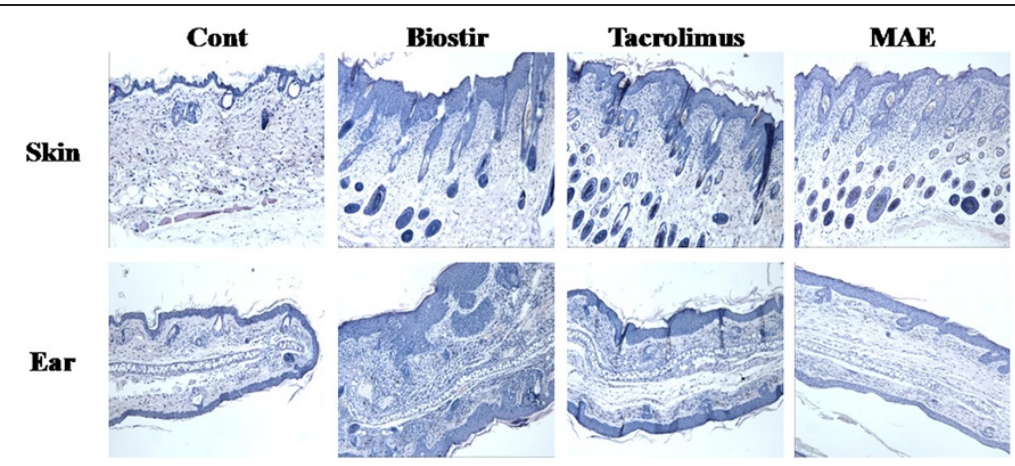

Figure 5 Effects of MAE on the histological features of house dust mite-induced atopic dermatitis in NC/Nga mice. The skin and ear tissues were excised from normal control group (vehicle-treated mice; 70\% ethanol, $200 \mu \mathrm{L} / \mathrm{mouse}$ ), Biostir group (Biostir-AD plus vehicle-treated mice), Tacrolimus group (Biostir-AD plus Tacrolimus ointment-treated mice; 50 mg/mouse), and MAE group (Biostir-AD plus MAE-treated mice; 10 mg/mouse), fixed with $10 \%$ formaldehyde, embedded in paraffin, and cut into thin sections. The histological features of the skin and ear lesions were determined after staining with hematoxylin and eosin.

with genetic and environmental components, such as infectious agents, food allergens, and aeroallergens. These environmental components elevate the serum IgE levels, which can be a strong trigger of infiltration by $\mathrm{T}$ cells, eosinophils, mast cells, macrophages, and keratinocytes [2].

Macrophages have a central role in the production of proinflammatory mediators during the inflammation response. Of the various proinflammatory mediators, nitrite and $\mathrm{PGE}_{2}$ have been found to be important in several physiological processes, including vasodilation, neurotransmission, blood coagulation, and immune regulation [19]. NO is synthesized by inducible NO synthase (iNOS), while $\mathrm{PGE}_{2}$ is produced by cyclooxygenase 2 (COX-2) [20,21]. They aggravate the inflammatory responses of atopic lesions, which are important feature is of atopic dermatitis [22]. In our study, we found that MAE reduced $\mathrm{NO}$ and $\mathrm{PGE}_{2}$ production in a dose-dependent manner in LPS stimulated RAW 264.7 macrophage cells.

Keratinocytes produce chemokines and these factors are involved with the development of inflammatory skin diseases, such as atopic dermatitis [23]. Chemokines can lead to a Th1/Th2 imbalance, which results in the development of atopic dermatitis lesions [4]. The lymphocytes that are directed to the skin have recently been shown to express CC chemokine receptor 4 , which is the receptor for the CC chemokine TARC. TARC is overexpressed by keratinocytes, especially in the epidermis of atopic dermatitis lesions in the murine model and atopic dermatitis patients [2]. In this study, MAE inhibited TARC production in TI-stimulated HaCaT cells. Overall, these results suggest that MAE is effective in suppressing inflammatory responses and the development of atopic dermatitis by reducing TARC production.
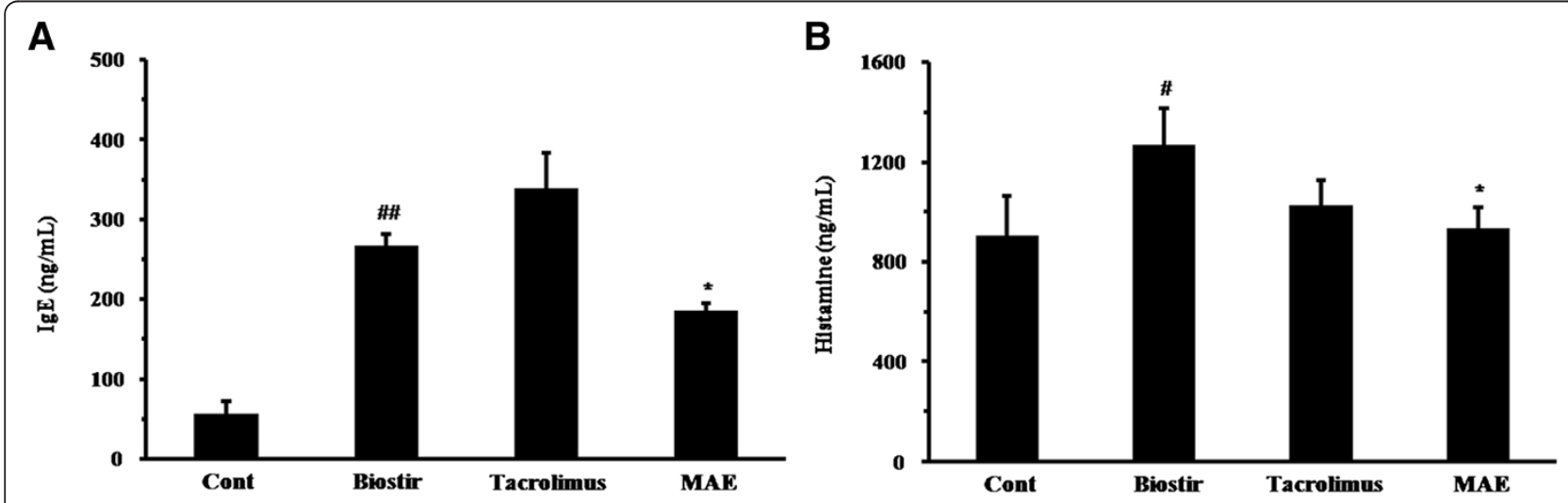

Figure 6 Effects of MAE on the plasma levels of IgE and histamine in house dust mite-induced atopic dermatitis in NC/Nga mice. The lgE and histamine levels were measured in plasma samples from normal control group (vehicle-treated mice; $70 \%$ ethanol, 200 $\mu \mathrm{L} / \mathrm{mouse}$ ), Biostir group (Biostir-AD plus vehicle-treated mice), Tacrolimus group (Biostir-AD plus Tacrolimus ointment-treated mice; 50 mg/mouse), and MAE group (Biostir-AD plus MAE-treated mice; $10 \mathrm{mg} / \mathrm{mouse}$ ). The plasma concentrations of IgE (A) and histamine (B) were measured by ELISA. The values are expressed the as mean \pm SEM $(n=5)$. ${ }^{\#, ~ \# \# ~} P<0.05$ and $P<0.01$ vs control group, respectively; ${ }^{*} P<0.05$ vs Biostir-AD-treated mice. 
$\mathrm{NC} / \mathrm{Nga}$ mice have been used as an animal model of atopic dermatitis and share the clinical features of human atopic dermatitis [24]. NC/Nga mice with atopic dermatitis exhibit various histopathological and pathophysiological changes compared with normal mice [25]. The elevation of proinflammatory cytokines, IgE, and histamine are important features in the pathophysiology of NC/Nga mice with atopic dermatitis [4]. Inflammatory cell infiltration, epidermis hypertrophy, intracellular edema, and hyperkeratosis are mainly observed in atopic dermatitis skin lesions [26]. Our study also observed the characteristic pathophysiological alterations of atopic dermatitis. NC/Nga mice where atopic dermatitis was induced by house dust mites exhibited increased levels of IgE and histamine in their plasma compared with normal mice. They also exhibited epidermis hypertrophy, intracellular edema, and infiltration of inflammatory cells in their skin lesions. By contrast, MAE-treated NC/Nga mice had reduced histopathological changes in their skin lesions and lower plasma IgE and histamine levels. Based on these findings, a topical application of MAE may be effective for suppressing the atopic dermatitis induced by house dust mites.

Topical steroids, emollients, and oral anti-histamines are used as the first-line therapy for atopic dermatitis [27]. Steroids are generally prescribed to control the symptoms of atopic dermatitis, but their repeated use can cause severe skin atrophy, susceptibility to infections, and other side effects. These profound side effects mean that chronic usage must be actively avoided. Thus, there is a strong need for the development of a herbal medicine that is effective for the treatment of atopic dermatitis, which should be safe and eco-friendly.

\section{Conclusions}

Our study demonstrated the inhibitory effects of MAE on atopic dermatitis. The inhibition of $\mathrm{NO}$ and $\mathrm{PGE}_{2}$ production was responsible for the anti-inflammatory effects of MAE, which may be associated with its inhibitory effect on TARC production by keratinocytes in dermatitis lesions. MAE also appeared to reduce the skin symptoms of atopic dermatitis, such as erythema, hemorrhage, and edema. The topical application of MAE significantly reduced the development of house dust mite-induced atopic dermatitis in NC/Nga mice. Overall, these findings provide scientific evidence that MAE has the potential to be developed as a therapeutic agent for the treatment of atopic dermatitis.

\section{Competing interests}

The authors have declared that no competing interests exist.

\section{Authors' contributions}

HSL and HKS participated in the design of the study data analyses and manuscript preparation. HSL, HH, HL, JKL, and MYL conducted the biological examination of in vitro and in vivo. All authors read and approved the final manuscript.

\section{Acknowledgments}

This work was supported by a grant from the Korea Institute of Oriental Medicine (No. K13030) and Korea Research Council of Fundamental Science \& Technology (KRCF, No. G10101), Korea.

Received: 14 August 2013 Accepted: 16 April 2014 Published: 23 April 2014

\section{References}

1. Leung DY: Atopic dermatitis: new insights and opportunities for therapeutic intervention. J Allergy Clin Immunol 2000, 105:860-876. 2. Leung DY, Bieber T: Atopic dermatitis. Lancet 2003, 361:151-160.

3. Fujii $Y$, Takeuchi H, Sakuma S, Sengoku T, Takakura S: Characterization of a 2,4-dinitrochlorobenzene-induced chronic dermatitis model in rats. Skin Pharmacol Physiol 2009, 22:240-247.

4. Yang G, Lee K, Lee MH, Kim SH, Ham IH, Choi HY: Inhibitory effects of Chelidonium majus extract on atopic dermatitis-like skin lesions in NC/Nga mice. J Ethnopharmacol 2011, 138:398-403.

5. Shiohara T, Hayakawa J, Mizukawa Y: Animal models for atopic dermatitis: are they relevant to human disease?". J Dermatol Sci 2004, 36:1-9.

6. Yuksel H, Kirmaz C, Yilmaz O, Pinar E, Vatansever S, Degirmenci PB, Ozbilgin K: Nasal mucosal expression of nitric oxide synthases in patients with allergic rhinitis and its relation to asthma. Ann Allergy Asthma Immunol 2008, 100:12-16.

7. Bae KH: The medicinal plants of Korea. Seoul, Korea: Kyo-Hak Publishing Co.; 2008:73.

8. Dugo P, Donato P, Cacciola F, Germano MP, Rapisarda A, Mondello L: Characterization of the polyphenolic fraction of Morus alba leaves extracts by HPLC coupled to a hybrid IT-TOF MS system. J Sep Sci 2009, 32:3627-3634.

9. Asano N, Yamashita T, Yasuda K, Ikeda K, Kizu H, Kameda Y: Polyhydroxylated alkaloids isolated from mulberry trees (Morus alba L.) and silkworms (Bombyx mori L.). J Agric Food Chem 2001, 49:4208-4213.

10. Katsube T, Imawaka N, Kawano Y, Yamazaki Y, Shiwaku K, Yamane Y: Antioxidant flavonol glycosides in mulberry (Morus alba L.) leaves isolated based on LDL antioxidant activity. Food Chem 2006, 97:25-31.

11. Kikuchi T, Nihei M, Nagai H, Fukushi H, Tabata K, Suzuki T, Akihisa T: Albanol A from the root bark of Morus alba L. induces apoptotic cell death in HL60 human leukemia cell line. Chem Pharm Bull 2010, 58:568-571.

12. Choi EM, Hwang JK: Effects of Morus alba leaf extract on the production of nitric oxide prostaglandin E2 and cytokines in RAW2647 macrophages. Fitoterapia 2005, 76:608-613.

13. Singab AN, El-Beshbishy HA, Yonekawa M, Nomura T, Fukai T: Hypoglycemic effect of Egyptian Morus alba root bark extract: effect on diabetes and lipid peroxidation of streptozotocin-induced diabetic rats. J Ethnopharmacol 2005, 100:333-338.

14. Arabshahi-Delouee $S$, Urooj A: Antioxidant properties of various solvent extracts of mulberry (Morus indica L.) leaves. Food Chem 2007, 102:1233-1240.

15. Ameen AM, Hapipah MA, Abdul AK, Mohd NS, Salmah I: Evaluation of the antiulcer activities of Morus alba extracts in experimentally induced gastric ulcer in rats. Biomed Res 2009, 20:35-39.

16. Lee YJ, Choi DH, Kim EJ, Kim HY, Kwon TO, Kang DG, Lee HS: Hypotensive hypolipidemic, and vascular protective effects of Morus alba L. in rats fed an atherogenic diet. Am J Chin Med 2011, 39:39-52.

17. Lee JK, Ha H, Lee HY, Park SJ, Jeong SL, Shin HK: Inhibitory effects of heartwood extracts of broussonetia kazinoki sieb on the development of atopic dermatitis in NC/Nga mice. Biosci Biotechnol Biochem 2010, 74:1802-1806

18. Hanifin JM, Thurston M, Omoto M, Cherill R, Tofte SJ, Graeber M: The eczema area and severity index (EASI): assessment of reliability in atopic dermatitis. Exp Dermatol 2001, 10:11-18.

19. Moncada S, Palmer RMJ, Higgs EA: Nitric oxide: physiology, pathophysiology, and pharmacology. Pharmacol Rev 1991, 43:109-142.

20. Mitchell JA, Larkin S, Williams TJ: Cyclooxygenase-2: regulation and relevance in inflammation. Biochem Pharmacol 1995, 50:1535-1542.

21. Cookson W: The immunogenetics of asthma and eczema: a new focus on the epithelium. Nat Rev Immunol 2004, 4:978-988.

22. Sandoval-López G, Teran LM: TARC: novel mediator of allergic inflammation. Clin Exp Allergy 2001, 31:1809-1812.

23. Hiramoto K, Kobayashi H, Ishii M, Sato E, Inoue M: Increased alphamelanocyte-stimulating hormone (alpha-MSH) levels and melanocortin 
receptors expression associated with pigmentation in an $\mathrm{NC} / \mathrm{Nga}$ mouse model of atopic dermatitis. Exp Dermatol 2010, 19:132-136.

24. Kim KC, Kim JS, Son JK, Kim IG: Enhanced induction of mitochondrial damage and apoptosis in human leukemia $\mathrm{HL}-60$ cells by the Ganoderma lucidum and Duchesnea chrysantha extracts. Cancer Lett 2007, 246:210-217.

25. Pokharel YR, Lim SC, Kim SC, Heo TH, Choi HK, Kang KW: Sopungyangjae-tang inhibits development of dermatitis in NC/Nga mice. Evid Based Complement Alternat Med 2008, 5:173-180.

26. Kobayashi H, Ishii M, Takeuchi S, Tanaka Y, Shintani T, Yamatodani A, Kusunoki T, Furue M: Efficacy and safety of a traditional herbal medicine, Hochu-ekki-to in the long-term management of kikyo (delicate constitution) patients with atopic dermatitis: A 6-month, multicenter, doubleblind, randomized, placebo-controlled study. Evidence-based Complementary and Alternative Medicine 2010, 7:367-373.

27. Berke R, Singh A, Guralnick M: Atopic dermatitis: an overview. Am Fam Physician 2012, 86:35-42.

doi:10.1186/1472-6882-14-139

Cite this article as: Lim et al:: Morus alba L. suppresses the development of atopic dermatitis induced by the house dust mite in NC/Nga mice.

BMC Complementary and Alternative Medicine 2014 14:139.

\section{Submit your next manuscript to BioMed Central and take full advantage of:}

- Convenient online submission

- Thorough peer review

- No space constraints or color figure charges

- Immediate publication on acceptance

- Inclusion in PubMed, CAS, Scopus and Google Scholar

- Research which is freely available for redistribution 